\title{
C-13 MAIN EXPRESSIONS OF SEQUENCE BOUN- DARIES AND FLOODING SURFACES IN THE CAMBRIAN OF THE SAHARAN PLATFORM (ALGERIA)
}

\begin{abstract}
The old "zone limits" (Ri, Ra, R2, R3), established by the Petroleum Companies which worked in the Algerian Sahara in the "sixties" (SN Repal, 1961; SN Repal et SNPA, 1962; CFP(A), 1960), have shown many deficiencies in long distance correlations. Recent works (Aït-salem et Soulali, 1993, 1994; Ait-salem et al; 1995, 1997, 1998; Zazoun et Aït-salem, 1998) have used the Sequence Stratigraphy concept and enhanced new sedimentological interpretations and more precise correlations. The siliciclastic cambrian series were then divided in third order sequences, systems tracts and parasequences.
\end{abstract}

Sequence Boundaries and Flooding Surfaces were evidenced by combining the descriptive characters, the diagraphy, the chemostratigraphy and the zircon typology.

Two kinds of Sequence Boundaries are distinguished:

- A type 2 sequence boundary,

- And a particular case of sequence boundary presenting a dual character (regressive and transgressive).

These two kinds of boundaries are characterized by very high values of major and trace elements just under them, and an appearance of several types of zircons.

\section{Three kinds of Flooding Surfaces are described:}

- Maximum Flooding Surfaces which show particularly high values of Boron,

- Transgressive Surface of Erosion

- And flooding surfaces bounding parasequences.

These three surfaces show together, just above them, an increase of values of major and trace elements and a sudden disappearance of several types of zircons.

These results allow us to establish more detailed long distance correlations and help to predict new potential reservoirs in this platform. 